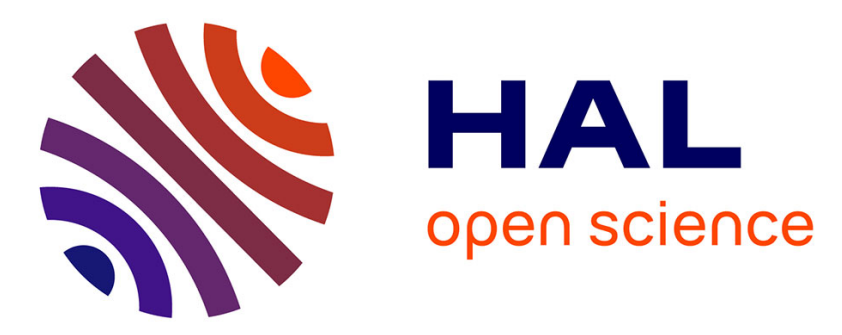

\title{
Evaluation of the STICS crop growth model with maize cultivar parameters calibrated for Eastern Canada
}

\author{
Jégo, Pattey, Bourgeois, Craig Drury, Tremblay
}

\section{To cite this version:}

Jégo, Pattey, Bourgeois, Craig Drury, Tremblay. Evaluation of the STICS crop growth model with maize cultivar parameters calibrated for Eastern Canada. Agronomy for Sustainable Development, 2011, 31 (3), pp.557-570. 10.1007/s13593-011-0014-4 . hal-00930481

\section{HAL Id: hal-00930481 \\ https://hal.science/hal-00930481}

Submitted on 1 Jan 2011

HAL is a multi-disciplinary open access archive for the deposit and dissemination of scientific research documents, whether they are published or not. The documents may come from teaching and research institutions in France or abroad, or from public or private research centers.
L'archive ouverte pluridisciplinaire HAL, est destinée au dépôt et à la diffusion de documents scientifiques de niveau recherche, publiés ou non, émanant des établissements d'enseignement et de recherche français ou étrangers, des laboratoires publics ou privés. 


\title{
Evaluation of the STICS crop growth model with maize cultivar parameters calibrated for Eastern Canada
}

\author{
Guillaume Jégo • Elizabeth Pattey • Gaétan Bourgeois • \\ Craig F. Drury $\bullet$ Nicolas Tremblay
}

Accepted: 20 October 2010 /Published online: 11 March 2011

(C) INRA and Springer Science+Business Media B.V. 2011

\begin{abstract}
Crop growth models are great tools for studying and anticipating the future impacts of rising demands for agricultural production while satisfying constraints with respect to product safety, the landscape, and the environment. Before crop growth models can be applied, however, they need to be calibrated and evaluated for cultivars representative of a given ecozone. This study presents an evaluation of the STICS crop growth model using maize cultivar parameters calibrated for the Mixedwood Plains ecozone in Eastern Canada. In the study area, which extends from southwestern Quebec to southern Ontario, the available crop heat units (CHU, in $\mathrm{CHU}$ index) for plant growth vary between 2,500 and 3,500 CHU. One cultivar was first calibrated in the STICS model using leaf area index (LAI) and yield data from Ottawa, Ontario. The model gave good predictions of LAI, biomass, and yield for the cultivar CanMaïsNE in the range of 2,500-2,900 CHU. The root mean square error of the predictions was $28.1 \%$ for LAI, $17.5 \%$ for biomass, and $10.1 \%$ for yield. A second
\end{abstract}

G. Jégo $\cdot$ E. Pattey $(\bowtie)$

Environmental Health, Research Branch,

Agriculture and Agri-Food Canada,

960 Carling Ave,

Ottawa, ON, Canada K1A 0C6

e-mail: Elizabeth.Pattey@agr.gc.ca

G. Bourgeois $\cdot$ N. Tremblay

Horticulture Research and Development Centre,

Agriculture and Agri-Food Canada,

430 Gouin Blvd,

Saint-Jean-sur-Richelieu, QC, Canada J3B 3E6

C. F. Drury

Greenhouse and Processing Crops Research Centre,

Agriculture and Agri-Food Canada,

2585 County Road 20,

Harrow, ON, Canada N0R 1G0 cultivar, CanMaïsSE, was defined for the higher $\mathrm{CHU}$ range (2,900-3,300 CHU). CanMaïsSE had the same crop and cultivar parameters as CanMaïsNE except for the duration of grain filling, which was increased by $6-7$ days to account for the longer growing season in the area with 3,300 CHU. Good predictions of LAI, biomass, and yield were obtained for CanMaïsSE, with root mean square error values of $30.6 \%, 25.2 \%$, and $16.1 \%$, respectively. Defining these two generic maize cultivars was sufficient to estimate biomass, yield, and LAI over the entire study area. This work is the first calibration and performance evaluation of the STICS crop model for maize in North America. Moreover, these new grain maize cultivars, adapted to a shorter growing season, open new opportunities for using STICS in northern countries.

Keywords STICS - Crop model - Maize - Eastern Canada . LAI · Biomass · Yield prediction · Earth observation

\section{Introduction}

Agriculture will have to meet rising demands for food, feed, fiber, and fuel over the course of the current century while satisfying constraints with respect to product safety, the landscape, and the environment (Spiertz 2010). Crop growth models will become essential tools for optimizing agriculture production with regard to environmental forcing conditions while facing these growing challenges. Crop growth models predict yield potential and nitrogen and water use under given climatic conditions and account for growth-limiting factors such as drought, heat, and frost (Gonzalez-Dugo et al. 2010). Crop growth models can be used to refine management practices, especially for fertilizer usage and timing, by simulating crop productivity in 
response to regionally observed climatic variations (Singh et al. 2008). For producers and crop insurance companies, crop models can be used to explain and gage the main abiotic-limiting factors leading to crop yield reduction. The basic spatial scale of most crop models is the homogeneous field plot unit (CERES, Ritchie and Otter 1984; EPIC, Williams et al. 1984; CropSyst, Stockle et al. 1994; STICS, Brisson et al. 1998, 2002, 2003; DSSAT, Jones et al. 2003). However, there are advantages to analyzing an agricultural system from a regional perspective. Indeed, agricultural recommendations and policies defined to address future agriculture challenges are generally implemented at the regional level. Using crop models over a region is helpful for estimating productivity, environmental impact, and water needs for agriculture and thus refining land use and crop rotation sequences accordingly. Regional crop modeling requires input data on soil, weather from national or regional databases, and management practices, data that are not always readily available. Information on management practices can to some extent be derived from multitemporal remote sensing observations. Because crop classification will not give any insight into the kind of cultivars being planted, the definition, calibration, and evaluation of a minimal set of generic cultivars in the crop growth model can be helpful for regional modeling.

This study presents the initial steps (model calibration and performance evaluation) in the regional-scale modeling of two generic maize (Zea mays L.) cultivars representative of the Mixedwood Plains ecozone in Eastern Canada (Fig. 1). Maize is the third largest grain crop cultivated in Canada (after wheat and canola) and the most important crop in Eastern Canada (Agriculture and Agri-Food Canada 2010). The region extending from southwestern Quebec to southern Ontario, which includes most of the Mixedwood Plains ecozone, is the northernmost area for maize cropping in North America. In this region, the maize-growing season begins between early May and early June and finishes in October. Maize cultivars are rated based on cumulative temperature in the growing season (crop heat units, CHU; Brown and Bootsma 1993). Daily CHU are calculated by using the average of a night time and a daytime values calculated from minimum and maximum temperatures using linear and curve relationships for night time and daytime, respectively. Because $\mathrm{CHU}$ varies from 2,500 to 3,500 in the Mixedwood Plains ecozone, at least two cultivars are required to provide acceptable predictions of leaf area index (LAI), biomass, and yield over the area. The growing season is about 5-15 days longer in southern Ontario than in the Ottawa area (Ontario Ministry of Agriculture and Rural Affairs 2002). Precipitations are considerable (500-600 mm from April to October) and sufficient to allow rainfed cropping. However, inter-annual variability and uneven distribution in terms of precipitations may cause crop water stress periods during some growing seasons. A large multi-annual dataset including contrasted climatic conditions is therefore required to assess the model's capability to accurately simulate crop growth in response to climatic variability. This capability should also be useful for running the model under future climate scenarios and testing the response of maize exposed to more extreme climatic conditions by altering the means and variances of climatic variables (Porter and Semenov 2005).

Since the 1940s, the average maize grain yield per hectare in Ontario has increased at a rate of approximately $1.5 \%$ per year (Tollenaar and $\mathrm{Wu} 1999$ ). Yield and biomass improvements can be attributed to the capacity of newer hybrids to tolerate environmental stresses (Ma and Dwyer 1998; Tollenaar and Wu 1999) and higher plant densities (Tollenaar 1991). Moreover, these hybrids are able to maintain higher concentrations of water and chlorophyll in their leaves at maturity; this ability is called the staygreen trait (Thomas and Smart 1993).

A short growing season compared to Western Europe (where the STICS crop model was developed), a rainfed cropping system, and the continuous improvement of maize cultivars are three important aspects in calibrating and evaluating the performance of crop models used to predict agronomic outputs such as LAI, biomass, or yield for maize in Eastern Canada. In addition, although several studies have examined the application of crop models in Western Canada, mainly for wheat (Walker 1989; Moulin and Beckie 1993; Touré et al. 1995; Chipanshi et al. 1997, 1999), few studies have examined crop modeling in Eastern Canada. Roloff et al. (1998) evaluated the EPIC crop model for maize and soybean yield predictions in Eastern Canada. The yields were predicted very well, although the cultivars were not calibrated for the range of climatic conditions in Eastern Canada. Further, the datasets used to evaluate model performance were limited to 4 years. Further analysis is therefore required to develop an accurate crop growth model for Eastern Canada.

The STICS crop growth model, which represents the latest generation of dual-purpose models that simulate agronomic and environmental outputs, has two main features of interest to regional modeling. First, STICS has an open architecture, which provides easy access to all parameters for cultivar calibration. A set of 10 cultivar parameters relating to crop phenology, LAI dynamics, and yield can be calibrated in response to regional conditions without altering the generic crop parameters (about 200). Second, the STICS model has a built-in capability to use LAI from an external source, such as remote-sensing data. Leaf area index can be used as a driving variable or to reinitialize input parameters such as seeding date or seeding density, as shown by Prévot et al. (2003) in the case of a winter wheat crop in southern France. No remote-sensing 
Fig.1 Map of crop heat units in the study area and location of the experimental sites

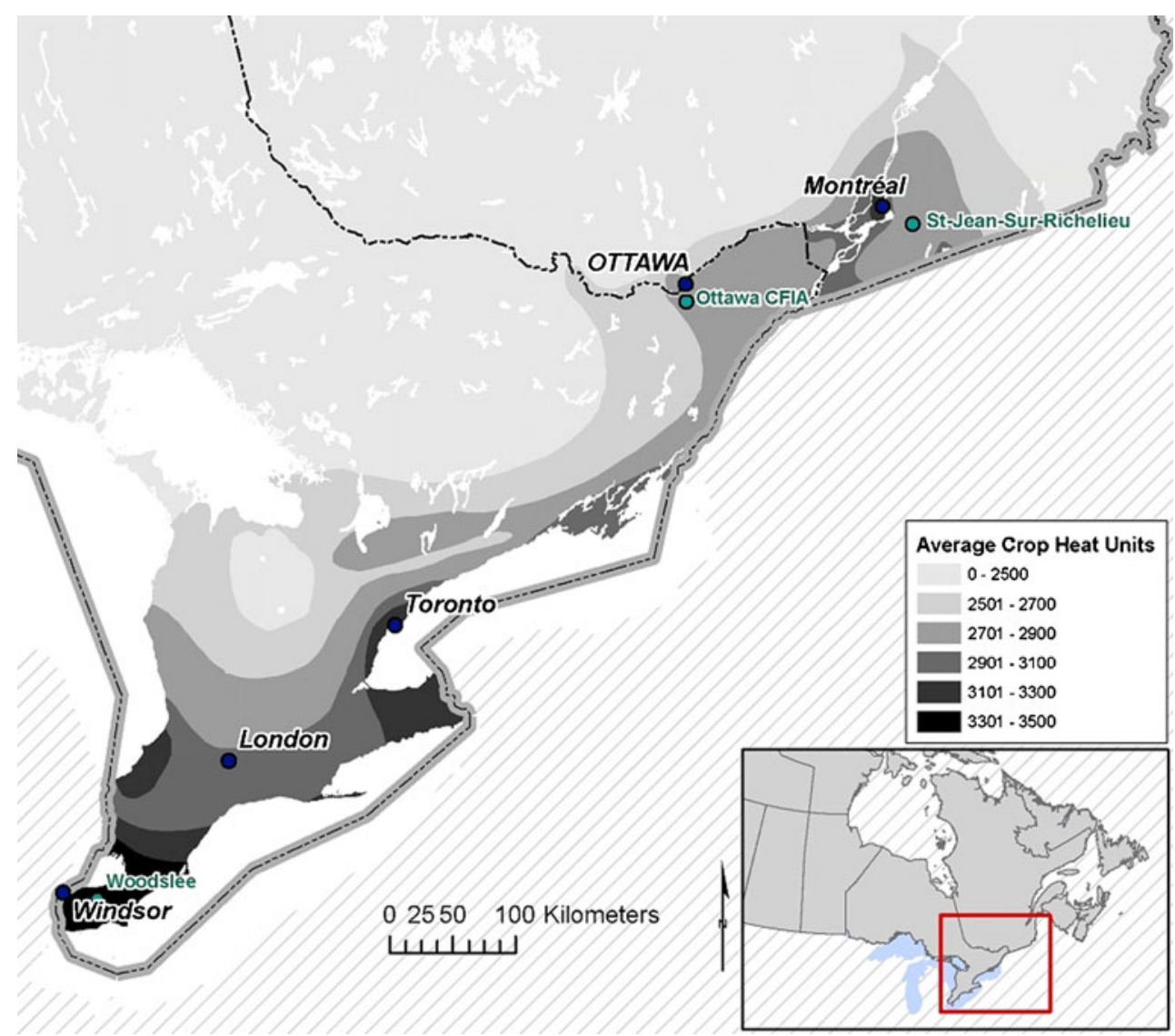

data were used in the present study, but this feature would be very helpful for running the model at the regional scale.

The objectives of this study were (1) to calibrate the STICS crop model for simulating the growth of two maize cultivars adapted to the growing conditions of Eastern Canada and (2) to evaluate the performance of the model for predicting LAI, biomass, and yield with the two cultivars across a large area extending approximately to $1,000 \mathrm{~km}$. This work constitutes the first calibration of STICS to a maize cultivar adapted to a short-growing season. It was hypothesized that two regional cultivars could be used to obtain good predictions of shoot dry biomass, LAI, and yield over the region of interest. This capability would represent a great advantage for crop modeling at the regional scale when coupled with remote sensing, because it decreases the number of unknown input parameters.

\section{Materials and methods}

The general methodology for adding new crops or cultivars to STICS was adapted from the method proposed by the STICS development team and used in other studies (Flénetet al. 2004; Jégo et al. 2010). In the present case, the three steps were as follows: (1) evaluating the performance of the STICS model using cultivars previously calibrated for European soil and climatic conditions; (2) calibrating a subset of parameters describing the cultivars in the model using one dataset representative of the study area; and (3) evaluating the model predictions of LAI, biomass, and yield, using the calibrated cultivars for 39 datasets independent of the calibration dataset (except for two datasets, which had the same soil properties). The calibration was also based on a review of previous studies describing cultivar properties and improvements in Eastern Canada (Tollenaar 1991; Ma and Dwyer 1998).

\subsection{Study sites and experiments}

The STICS model was calibrated and evaluated in Quebec and Ontario for the prediction of the shoot biomass, LAI, and yield of maize with two regionally adapted generic cultivars (CanMaïsNE and CanMaïsSE). A large dataset of 40 experiments at three sites over 15 years (1994-2008) was used to calibrate and evaluate the performance of these two cultivars for most of the Mixedwood Plains ecozone of Eastern Canada (Fig. 1).

The first experimental site was composed of four fields located near Saint-Jean-sur-Richelieu $\left(45^{\circ} 19^{\prime} \mathrm{N}, 73^{\circ} 21^{\prime} \mathrm{W}\right.$, St-Jean, QC, Canada). The average available CHU at that site was about 2,950. The second site, located on the 
Canadian Food Inspection Agency (CFIA) and Greenbelt experimental farms $\left(45^{\circ} 18^{\prime} \mathrm{N}, 75^{\circ} 45^{\prime} \mathrm{W}\right.$, Ottawa, ON, Canada), had average CHU of 2,890. The third site, on Agriculture and Agri-Food Canada's Hon. Eugene F. Whelan Experimental Farm $\left(42^{\circ} 13^{\prime} \mathrm{N}, 82^{\circ} 44^{\prime} \mathrm{W}\right.$, Woodslee, near Windsor, ON, USA), was located in southern Ontario and had a CHU rating of 3,400 .

Precipitations were almost equally distributed over the study area (Table 1) and were sufficient to allow rainfed cropping. However, higher temperatures (and potential evapotranspiration) would influence the water balance. Bootsma (2009, unpublished data, http://sites.google.com/ site/andybootsma/home/water-deficit-trends) showed that, from 1996 to 2005, the annual water deficit was about $60 \mathrm{~mm}$ higher in Windsor than in Ottawa. Conventional agricultural practices, representative of standard maize field cultivation in Eastern Canada, were followed for seeding, fertilization, and chemical weed control (Ontario Ministry of Agriculture and Rural Affairs 2002).

\subsubsection{Saint-Jean-sur-Richelieu (St-Jean)}

Four field trials were conducted at the experimental site near Saint-Jean-sur-Richelieu (St-Jean; Table 2). The dominant

Table 1 Climatic data recorded from April to October at the on-site weather stations, and comparison with the average climatic data from 1971 to 2000 (Environment Canada)

\begin{tabular}{|c|c|c|c|c|c|c|}
\hline Location & Year & Sum rainfall $(\mathrm{mm})$ & Sum radiation $^{\mathrm{a}}\left(\mathrm{MJ} \mathrm{m}^{-2}\right)$ & $\begin{array}{l}\text { GDD } 8^{\circ} \mathrm{C} \\
\text { base }{ }^{\circ} \mathrm{C} \text { days }\end{array}$ & $\begin{array}{l}\text { GDD } 10^{\circ} \mathrm{C} \\
\text { base }{ }^{\circ} \mathrm{C} \text { days }\end{array}$ & CHU index \\
\hline \multirow[t]{5}{*}{ St-Jean (L'Acadie) } & 2004 & 527 & 3,586 & 1,518 & 1,178 & 2,963 \\
\hline & 2005 & 891 & 3,567 & 1,701 & 1,360 & 3,180 \\
\hline & 2006 & 858 & 3,302 & 1,577 & 1,237 & 3,057 \\
\hline & 2007 & 757 & 3,515 & 1,613 & 1,266 & 2,971 \\
\hline & Average 1971-2000 & 629 & NA & 1,596 & 1,157 & 2,950 \\
\hline \multirow[t]{10}{*}{ Ottawa CFIA } & 1994 & 615 & 3,610 & 1,476 & 1,148 & 2,829 \\
\hline & 1995 & 648 & 3,794 & 1,593 & 1,253 & 3,028 \\
\hline & 1996 & 538 & 3,531 & 1,450 & 1,134 & 2,887 \\
\hline & 1998 & 486 & 3,780 & 1,749 & 1,386 & 3,310 \\
\hline & 2000 & 555 & 3,475 & 1,334 & 1,006 & 2,750 \\
\hline & 2001 & 489 & 3,813 & 1,685 & 1,337 & 3,053 \\
\hline & 2002 & 603 & 3,662 & 1,715 & 1,394 & 2,946 \\
\hline & 2006 & 789 & 3,544 & 1,570 & 1,238 & 3,015 \\
\hline & 2008 & 643 & 3,866 & 1,514 & 1,177 & 2,931 \\
\hline & Average 1971-2000 & 579 & NA & 1,626 & 1,190 & 2,890 \\
\hline \multirow[t]{16}{*}{ Woodslee } & 1994 & 444 & 3,986 & 1,811 & 1,445 & 3,438 \\
\hline & 1995 & 439 & 3,700 & 1,911 & 1,553 & 3,487 \\
\hline & 1996 & 537 & 3,688 & 1,854 & 1,498 & 3,339 \\
\hline & 1997 & 470 & 3,740 & 1,678 & 1,340 & 3,121 \\
\hline & 1998 & 420 & 3,926 & 2,054 & 1,666 & 3,772 \\
\hline & 1999 & 398 & 4,036 & 2,086 & 1,711 & 3,718 \\
\hline & 2000 & 735 & 3,725 & 1,911 & 1,530 & 3,527 \\
\hline & 2001 & 598 & 3,809 & 2,013 & 1,640 & 3,606 \\
\hline & 2002 & 476 & 3,827 & 2,045 & 1,702 & 3,407 \\
\hline & 2003 & 556 & 3,739 & 1,797 & 1,432 & 3,311 \\
\hline & 2004 & 577 & 3,723 & 1,900 & 1,530 & 3,471 \\
\hline & 2005 & 295 & 3,959 & 2,151 & 1,780 & 3,782 \\
\hline & 2006 & 584 & 3,845 & 1,953 & 1,580 & 3,657 \\
\hline & 2007 & 445 & 4,008 & 2,102 & 1,714 & 3,782 \\
\hline & 2008 & 519 & 4,050 & 1,867 & 1,494 & 3,103 \\
\hline & Average $1971-2000$ & 578 & NA & 2,000 & 1,548 & 3,410 \\
\hline
\end{tabular}

Growing degree days (GDD) were calculated with the method proposed by Arnold (1960) and crop heat units (CHU) were calculated with the method proposed by Brown and Bootsma (1993)

${ }^{\mathrm{a}} N A$ not applicable 
Table 2 Management practices and number of measurements at the study sites for calibration of new cultivars and evaluation of model performance

\begin{tabular}{|c|c|c|c|c|c|c|c|c|c|c|c|c|}
\hline & \multirow[t]{2}{*}{ Location } & \multirow[t]{2}{*}{ Year } & \multirow[t]{2}{*}{ Field } & \multirow{2}{*}{$\begin{array}{l}\text { Cultivar } \\
\text { name }^{\mathrm{a}}\end{array}$} & \multirow{2}{*}{$\begin{array}{l}\text { Crop } \\
\text { heat units }\end{array}$} & \multirow{2}{*}{$\begin{array}{l}\text { Seeding } \\
\text { date }\end{array}$} & \multirow{2}{*}{$\begin{array}{l}\text { Harvest } \\
\text { date }\end{array}$} & \multirow{2}{*}{$\begin{array}{l}\mathrm{N} \text {-fertilization } \\
\mathrm{kg} \mathrm{N}^{-1}\end{array}$} & \multicolumn{3}{|c|}{ Number of measurements } & \multirow[t]{2}{*}{ Yield } \\
\hline & & & & & & & & & $\begin{array}{l}\text { Green } \\
\text { LAI }^{\mathrm{b}}\end{array}$ & $\begin{array}{l}\text { Total } \\
\text { LAI }^{\mathrm{b}}\end{array}$ & Biomass & \\
\hline Calibration & $\begin{array}{c}\text { Ottawa CFIA } \\
\text { farm }(\mathrm{ON})\end{array}$ & 1998 & 25 & Pioneer 3893 & 2,800 & 17 May & 13 Oct & 155 & 8 & 0 & 7 & Yes \\
\hline \multirow[t]{39}{*}{ Evaluation } & St-Jean (QC) & 2004 & 31 & Pioneer 38A24 & 2,900 & 12 May & 28 Oct & 151 & 0 & 8 & 8 & Yes \\
\hline & & 2005 & 32 & Dekalb 4627 & 2,950 & 12 May & $14 \mathrm{Nov}$ & 135 & 0 & 8 & 9 & Yes \\
\hline & & 2005 & 32 & Dekalb 4627 & 2,950 & 12 May & 14 Nov & 188 & 0 & 8 & 9 & Yes \\
\hline & & 2006 & 33 & Dekalb 4627 & 2,950 & 9 May & 2 Nov & 135 & 0 & 6 & 7 & Yes \\
\hline & & 2006 & 33 & Dekalb 4627 & 2,950 & 9 May & 2 Nov & 188 & 0 & 6 & 7 & Yes \\
\hline & & 2007 & 34 & Dekalb 4627 & 2,950 & 3 May & 31 Oct & 120 & 0 & 7 & 8 & Yes \\
\hline & & 2007 & 34 & Dekalb 4627 & 2,950 & 3 May & 31 Oct & 165 & 0 & 7 & 8 & Yes \\
\hline & & 1994 & 19 & NA & & 20 May & $16 \mathrm{Nov}$ & 138 & 13 & 0 & 13 & No \\
\hline & & 1995 & 25 & Pioneer 3921 & 2,760 & 24 May & 16 nov & 137 & 14 & 0 & 13 & No \\
\hline & & 1996 & 19 & Pride K 135 & & 22 May & 15 Nov & 144 & 11 & 0 & 11 & No \\
\hline & & 2000 & 25 & Pioneer 3905 & 2,775 & 28 May & $5 \mathrm{Nov}$ & 170 & 7 & 0 & 3 & Yes \\
\hline & & 2001 & 23 & Pioneer 3905 & 2,275 & 1 May & 10 Oct & 168 & 3 & 0 & 4 & Yes \\
\hline & & 2001 & 13 & NA & & 9 May & 17 Oct & 118 & 3 & 0 & 4 & Yes \\
\hline & & 2002 & 14 & Pioneer 39D82 & 2,625 & 22 May & 22 Oct & 155 & 6 & 0 & 6 & Yes \\
\hline & & 2006 & 14 & Pioneer 39D82 & 2,625 & 10 May & $7 \mathrm{Nov}$ & 136 & 5 & 0 & 6 & Yes \\
\hline & & 2008 & 2 & NA & & 13 May & 31 Oct & 157 & 0 & 0 & 6 & No \\
\hline & & 2008 & 5 & NA & & 13 May & 31 Oct & 157 & 0 & 0 & 6 & No \\
\hline & & 2008 & 9 & NA & & 10 jun & $15 \mathrm{Nov}$ & 125 & 3 & 0 & 7 & Yes \\
\hline & & 2008 & 11 & NA & & 13 May & 31 Oct & 157 & 3 & 0 & 6 & No \\
\hline & & 1994 & 42 & Pioneer 3573 & 3,220 & 19 May & $2 \mathrm{Nov}$ & 155 & 0 & 0 & 0 & Yes \\
\hline & & 1995 & 42 & Pioneer 3573 & 3,220 & 17 May & 4 Oct & 155 & 0 & 0 & 0 & Yes \\
\hline & & 1996 & 42 & Pioneer 3573 & 3,220 & 28 May & 4 Oct & 155 & 0 & 0 & 0 & Yes \\
\hline & & 1997 & 42 & Pioneer 3573 & 2,950 & 10 jun & 6 Nov & 175 & 0 & 0 & 7 & Yes \\
\hline & & 1998 & 42 & NK Max 21 & 3,250 & 21 May & $16 \mathrm{Nov}$ & 175 & 0 & 0 & 6 & Yes \\
\hline & & 1999 & 42 & NK Max 21 & 3,250 & 20 May & 29 Oct & 175 & 0 & 0 & 7 & Yes \\
\hline & & 2000 & 42 & NK Max 21 & 3,250 & 2 Jun & $15 \mathrm{Nov}$ & 175 & 0 & 0 & 0 & Yes \\
\hline & & 2001 & 42 & NK N58D1 & 3,300 & 7 May & $9 \mathrm{Nov}$ & 182 & 0 & 0 & 0 & Yes \\
\hline & & 2002 & 42 & NK N58D1 & 3,300 & 23 May & 23 Oct & 182 & 0 & 0 & 0 & Yes \\
\hline & & 2003 & 42 & NK N45-A6 & 3,100 & 17 Jun & 17 Nov & 180 & 0 & 0 & 0 & Yes \\
\hline & & 2004 & 42 & NK N45-A6 & 3,100 & 7 Jun & $16 \mathrm{Nov}$ & 150 & 0 & 0 & 0 & Yes \\
\hline & & 2005 & 42 & NK N58-D1 & 3,300 & 11 May & 31 Oct & 150 & 0 & 0 & 0 & Yes \\
\hline & & 2006 & 42 & NK N58-D1 & 3,300 & 29 May & $27 \mathrm{Nov}$ & 150 & 0 & 0 & 0 & Yes \\
\hline & & 2002 & 41 & NK N58D1 & 3,300 & 22 May & 23 Oct & 170 & 0 & 0 & 0 & Yes \\
\hline & & 2003 & 41 & NK N58D1 & 3,300 & 29 May & 6 Nov & 170 & 0 & 0 & 0 & Yes \\
\hline & & 2004 & 41 & NK N45-A6 & 3,100 & 5 Jun & 9 Nov & 170 & 0 & 0 & 0 & Yes \\
\hline & & 2005 & 41 & NK N58D1 & 3,300 & 10 May & 26 Oct & 170 & 0 & 0 & 0 & Yes \\
\hline & & 2006 & 41 & NK N58D1 & 3,300 & 30 May & $1 \mathrm{Nov}$ & 170 & 0 & 0 & 0 & Yes \\
\hline & & 2007 & 41 & NK N58D1 & 3,300 & 14 May & 31 Oct & 170 & 0 & 0 & 0 & Yes \\
\hline & & 2008 & 41 & NK N45A-GT/CB/LL & 3,100 & 7 May & 20 Oct & 170 & 0 & 0 & 0 & Yes \\
\hline
\end{tabular}

\footnotetext{
${ }^{\mathrm{a}} N A$ not applicable

${ }^{\mathrm{b}} L A I$ leaf area index
} 
soil texture was loam, except in field 31 , where it was silty clay (Table 3). Maize seeding took place between 3 and 12 May at densities of 7.9 seeds $\mathrm{m}^{-2}$ in 2004 and 2005, 7.4 seeds $\mathrm{m}^{-2}$ in 2006, and 7.0 seeds $\mathrm{m}^{-2}$ in 2007. Although different $N$ rates were tested in these experiments, only $N$ rates close to the recommended $N$ fertilization rate in Quebec (i.e., $120-170 \mathrm{~kg} \mathrm{Nha}^{-1}$; Centre de Référence en Agriculture et Agroalimentaire du Québec 2003) were used for model evaluation in this study. Nitrogen application was split between seeding and sidedress (at the six-leaf stage). Total LAI (determined with an LAI-2000 plant canopy analyzer; LI-COR, Lincoln, NE, USA) and shoot biomass were measured in these fields from emergence until maximum LAI. Final biomass (manual harvest) and grain yield (combine harvest) were also determined.

Climatic data were obtained from the automatic weather station at the Agriculture and Agri-Food Canada experimental farm in L'Acadie (near the St-Jean site). Precipitations and temperatures were higher than climate normals in 2005, 2006, and 2007 but slightly lower in 2004 (Table 1).

\subsubsection{CFIA and Greenbelt experimental farms}

On the CFIA and Greenbelt experimental farms, which are adjacent to each other and cover $16 \mathrm{~km}^{2}$, eight fields designated as fields $2,5,9,11,14,19,23$, and 25 were used in this study. The soil texture ranged from loam to clay loam, except for field 5, which was a sandy loam (Table 3). Key field management practices are indicated in Table 2. Maize was usually sown the third week of May. Seeding density ranged between 6.5 and 8.0 seeds $\mathrm{m}^{-2}$. The $N$ fertilization rate varied between 136 and $170 \mathrm{kgN} \mathrm{ha}^{-1}$, which coincides with the $N$ rate recommendations in Ontario (130-180 kg Nha ${ }^{-1}$ depending on the expected grain yield; Ontario Ministry of Agriculture and Rural Affairs 2002). Shoot biomass and either total LAI (determined with a LAI-2000) or green destructive LAI (determined with a LI-3000 portable leaf area meter; LI-COR) were measured several times during the growing season. Final shoot biomass (manual harvest) and yield (combine harvest) were also measured.

The weather station was located in field 25 from 1994 to 2001 and in field 14 from 2002 to 2008. The mean seasonal climatic data are summarized in Table 1. From April to October, precipitation ranged from 486 to $789 \mathrm{~mm}$ depending on the year. Drier than normal years were observed in 1996, 1998, and 2001, precipitations close to normal were observed in 2000, and wetter than normal years were observed in 1994, 1995, 2002, 2006, and 2008.

\subsubsection{Woodslee}

Data were collected from two maize-soybean-winter wheat rotation experiments initiated in 1994 and 2002 (Table 2). Conventional agricultural practices were followed for seeding, fertilization, and chemical weed control for the two experiments. The soil was a Brookston clay loam, which is the dominant soil type in Southwestern Ontario (Table 3). A randomized complete block design was used. For the experiment that ran from 1994 to 2006 (in field 42), each plot was $9 \times 20 \mathrm{~m}$, whereas for the study that was conducted from 2002 to 2008 (in field 41), each plot was $6.1 \times 20 \mathrm{~m}$. Maize was seeded between 7 May and 17 June. Seeding was delayed in 1997, 2000, 2003, and 2004 because of high spring precipitations. Seeding density varied between 7.1 and 7.8 seeds $\mathrm{m}^{-2}$. Nitrogen was applied at seeding and sidedress. Shoot biomass was measured several times during the growing season in

Table 3 Soil properties at the three experimental sites

\begin{tabular}{|c|c|c|c|c|c|c|c|}
\hline Location & Field & Canadian texture & Clay content $(\%)$ & Field capacity $(\%)$ & Wilting point $(\%)$ & Bulk density & $\mathrm{pH}$ \\
\hline \multirow[t]{4}{*}{ St-Jean (QC) } & 31 & Silty clay & 45.0 & 32.0 & 21.0 & 1.25 & 6.6 \\
\hline & 32 & Loam & 15.0 & 20.0 & 12.3 & 1.40 & 6.8 \\
\hline & 33 & Loam & 20.0 & 20.0 & 10.0 & 1.45 & 6.5 \\
\hline & 34 & Loam & 20.0 & 20.0 & 10.0 & 1.47 & 6.6 \\
\hline \multirow[t]{8}{*}{ Ottawa CFIA (ON) } & 2 & Loam & 25.0 & 24.2 & 12.6 & 1.32 & 6.8 \\
\hline & 5 & Sandy Loam & 10.6 & 15.0 & 6.0 & 1.30 & 6.0 \\
\hline & 9 & Loam & 25.0 & 24.2 & 12.6 & 1.32 & 6.8 \\
\hline & 11 & Loam & 25.0 & 24.2 & 12.6 & 1.32 & 6.8 \\
\hline & 14 & Loam & 25.0 & 24.2 & 12.6 & 1.32 & 6.8 \\
\hline & 19 & Clay loam & 32.5 & 25.4 & 14.6 & 1.38 & 7.0 \\
\hline & 23 & Clay loam & 30.0 & 24.4 & 14.1 & 1.38 & 6.0 \\
\hline & 25 & Loam & 27.1 & 21.4 & 11.9 & 1.35 & 6.6 \\
\hline \multirow[t]{2}{*}{ Woodslee $(\mathrm{ON})$} & 41 & Clay loam & 37.0 & 26.1 & 16.2 & 1.35 & 6.1 \\
\hline & 42 & Clay loam & 35.0 & 26.1 & 16.2 & 1.35 & 6.1 \\
\hline
\end{tabular}


1997, 1998, and 1999. Maize yields were measured for the entire plot area using a combine.

The climatic data were collected from a weather station located $1 \mathrm{~km}$ from the field. The year 2005 was very dry, with half the normal rainfall. Additionally, the years 1994, 1995, 1997, 1998, 1999, 2002, and 2007 were drier than normal, whereas 1996, 2001, 2003, 2004, 2006, and 2008 had close to normal rainfall. Precipitations in 2000 were significantly higher than the average for 1971-2000 (Table 1).

\subsection{STICS crop model}

The STICS crop model (version 6.9) is a dynamic soil-crop simulation model that runs on a daily basis. The crop is described in terms of its shoot dry biomass (carbon and nitrogen), its LAI, and the biomass (number and weight) of the harvested crop organs. Crop temperature (derived from air temperature using an empirical approach) was used to calculate the sum of degree days between phenological stages. The base temperature for maize growth and development $(\mathrm{Tb})$ used to calculate growing degree days (GDD) between phenological stages is $8^{\circ} \mathrm{C}$ (Brisson et al. 1998). The water routine calculates the water status of the soil and crop as well as the water stress indices that reduce leaf growth and net photosynthesis in plants. The water routine estimates the water requirements of the soil-leaf system as well as the water supply to the soil-root system.

The input soil property data required to run the model are the organic $\mathrm{N}$, clay, and carbonate contents in the plowed layer. Field capacity, wilting point, and bulk density are required for all simulated soil layers. The following daily weather data are also required: daily minimum and maximum temperatures, solar radiation, rainfall, and calculated potential evapotranspiration. The model inputs for crops are as follows: seeding date, depth, and density; rate and date of mineral and organic fertilization; amount and date of irrigation; and date and depth of soil tillage, including the description of crop residues and organic products returned to the soil, given that the model also accounts for the decomposition of crop residues. The STICS model was initially parameterized and evaluated for bare soil, wheat, and maize (Brisson et al. 1998). It has since been adapted for other crops such as oilseed rape, sunflower, soybean, flax, tomato, sorghum, lettuce, mustard, sugar beet, and potato (Brisson et al. 2003). On a daily basis, it is possible to predict more than 200 output variables, including green LAI, shoot dry biomass, and dry biomass of harvested organs, which were the output variables analyzed in this study.

\subsection{Model parameterization}

Soil input parameters were obtained from soil analyses or derived from those analyses using pedo-transfer functions
(Saxton and Rawls 2006). Soil depth and maximum rooting depth were set at $1 \mathrm{~m}$ for the Ottawa CFIA and St-Jean sites and at $0.8 \mathrm{~m}$ for the Woodslee site, in accordance with the average groundwater level during the growing season. Input weather data files, including wind speed and relative humidity, were created using the data from the local weather stations. Potential evapotranspiration was calculated with the Penman formula (Monteith 1965). Actual management practices, such as seeding date, seeding density, tillage, $N$ fertilization rate, and $N$ application, were also used for each simulation. Simulations were performed from 15 April to 30 November. The initial soil water content was set at field capacity, which is representative of soil water status after snow melt. Initial soil inorganic $N$ was set at a value between 20 and $80 \mathrm{~kg} \mathrm{Nha}^{-1}$ depending on the measurements of soil $N$ content gathered at Ottawa CFIA and StJean. At Woodslee, an average inorganic $N$ content of $50 \mathrm{~kg} \mathrm{Nha}^{-1}$ was used.

\subsection{Selection of European cultivars}

In a preliminary step, the model predictions with the nine European maize cultivars already defined in STICS were evaluated by comparing LAI, biomass, and yield predictions to the measurements at the CFIA experimental site in 1998, which was one of the most complete datasets for green LAI, shoot biomass, yield, and full crop management data. The best cultivars (which had a lower mean error (ME) and root mean square error (RMSE) and the best agreement between predicted and actual phenological stages) were then selected as a reference for the calibration procedure.

The model predicted LAI, biomass, and yield better with the short-growing season cultivars. The cultivar DK 250 gave the best prediction for LAI and biomass, but yield was overestimated. Given that the cultivar Pactol presented a shorter duration of grain filling (stdrpmat parameter, Table 4), that cultivar gave a better prediction of final grain yield and was therefore used as a reference for the calibration procedure. With this cultivar, the maximum LAI was well predicted, but both the growing season and the predicted harvest were still too long. In addition, the predicted emergence date was about 18 days too late.

\subsection{Cultivar calibration in the Mixedwood Plains ecozone}

The calibration procedure was divided into two steps. First, CanMaïsNE, adapted for a low CHU range $(2,500-$ 2,900 CHU), was calibrated using the 1998 CFIA dataset. That dataset was selected for the calibration because it contained a wide range of green LAI measurements up to senescence. The weather conditions in 1998 were slightly warmer and drier than the averages for 1971-2000. The 
Table 4 Parameters of the reference cultivar already defined in STICS (Pactol) and of the cultivars CanMaïsNE and CanMaïsSE for the Mixedwood Plains ecozone

Cultivar parameers ${ }^{\mathrm{a}}$

\begin{tabular}{lllllllll}
\hline Cultivars & stlevamf & satmflax & stlevdrp & stdrpmat & durvieF & pgrainmax & nbgrmax & Growing season $^{\text {b }}$ \\
Pactol & 253 & 507 & 1,080 & 600 & 200 & 0.296 & 4,200 & 1,680 \\
CanMaïsNE & 253 & 500 & 1,050 & 420 & 210 & 0.260 & 4,500 & 1,470 \\
CanMaïsSE & 253 & 500 & 1,050 & 475 & 220 & 0.360 & 4,500 & 1,525 \\
\hline
\end{tabular}

${ }^{\text {a }}$ stlevamf degree days between emergence and the maximum leaf growth rate; stamflax degree days between the maximum leaf growth rate and the maximum leaf area index; stlevdrp degree days between emergence and the beginning of grain filing; stdrpmat degree days between the beginning of grain filling and maturity; durvieF maximum lifespan of an adult leaf; pgrainmax maximum weight of one grain (g); nbgrmax maximum number of grains.

${ }^{\mathrm{b}}$ Growing season stlevdrp + stdrpmat. Cumulative degree-days were calculated on a base temperature (Tb) of $8^{\circ} \mathrm{C}$

final shoot biomass and grain yield were close to the average values reported at the three sites. The calibration involved first adjusting the cultivar-specific parameters while keeping the plant parameters unchanged. Some of the cultivar parameters, such as the duration of the vegetative (stlevdrp) and reproductive (stdrpmat) stages and the yield parameters (pgrainmax and nbgrmax), were adjusted directly according to the observed values in the selected dataset used for calibration. The parameters controlling LAI dynamics (stlevamf, stamflax, and durvieF) were calibrated by adjusting the LAI curve to the LAI measurements of the selected experiment. Some of the general plant parameters (i.e., duration of emergence and radiation use efficiency [RUE]) were then calibrated to resolve issues remaining after calibration of the cultivar parameters were completed. Finally, the relevance of the new parameter values was evaluated according to cultivar properties and improvements in eastern Canada.

CanMaïsSE, which was adapted to the highest CHU range $(2,900-3,400 \mathrm{CHU})$, was defined by adjusting the parameters controlling the duration of grain filling and the lifespan of the leaves. All other parameters were assumed to be identical to CanMaïsNE.

\subsection{Cultivar performance evaluation in the Mixedwood Plains ecozone}

All datasets were used for the performance evaluation of the newly calibrated cultivars adapted to the Mixedwood Plains, excluding the 1998 CFIA dataset used for the calibration procedure (Table 2). A good prediction of the LAI dynamics means that the phenological parameters are well calibrated in the model. Comparisons were made between the observed and simulated dates of emergence and harvest, the durations of grain filling, and the final biomass and grain yield values for the newly calibrated cultivars. Model performance was evaluated by location and by cultivar (CanMaïsNE and CanMaïsSE). For the Ottawa CFIA site, the performance of CanMaïsNE was evaluated. For the Woodslee site, CanMaïsSE was used when seeding occurred before 1 June, and CanMaïsNE was used when seeding occurred after 1 June (i.e., in 1997, 2000,2003 , and 2004), in order to take the shorter growing season into account. The cultivars seeded at the St-Jean site presented CHU close to the average for the study area. The performance of both cultivars (CanMaïsNE and CanMaïsSE) was evaluated at St-Jean.

The statistical evaluation of model performance for the prediction of either LAI or shoot dry biomass was accomplished by comparing the model estimates to all the observations over a given growing season. The criteria used to calibrate and evaluate the model were the slope and intercept of the linear regression, the coefficient of determination $\left(R^{2}\right)$, the RMSE, and the ME. The $R^{2}$ provides an estimate of the reliability and strength of the linear model. The RMSE indicates the error of prediction of the model by giving more weight to high errors. A low value for RMSE, expressed as a percentage of the measurement average, means that the prediction ability of the model is good. The $\mathrm{ME}$ gives an estimate of the bias of the model. A low value for $\mathrm{ME}$, expressed as a percentage of the measurement average, indicates that there is little bias.

Jamieson et al. (1991) provided an estimate of the accuracy of the simulation according to the RMSE value. The simulation is supposed to be excellent when RMSE $\leq$ $10 \%$, good when $10 \%<\mathrm{RMSE} \geq 20 \%$, fair when $20 \%<$ RMSE $\geq 30 \%$, and poor when RMSE $>30 \%$. Given the greater uncertainty of LAI measurements (Chen and Black 1992; Pokorný and Marek 2000), the RMSE value for LAI would be expected to be slightly higher than the RMSE value for biomass.

\section{Results and discussion}

\subsection{Cultivar calibration in the Mixedwood Plains ecozone}

The 1998 dataset was also used for calibrating the new cultivars. Most of the phenological parameters were kept close to those of the reference cultivar (Pactol), with the 
exception of the duration of grain filling, which was greatly reduced (stdrpmat parameter). In 1998, the observed beginning of the reproductive stage ranged from 23 July to 4 August, and maturity was reached between 11 and 24 September. After calibration, the predicted grain filling period started on 27 July and ended on 17 September, which was within the range of dates observed in the field study. The predicted duration of grain filling was 52 days (582 GDD with $\mathrm{Tb}=8^{\circ} \mathrm{C}$ ), which was close to the duration found by Dwyer et al. (1994) at a study site within $100 \mathrm{~km}$ of Ottawa. The calibration of the duration of grain filling did not significantly affect the predicted LAI and biomass, with RMSE values of $26.8 \%$ and $31.9 \%$, respectively, compared to $27.1 \%$ and $31.9 \%$ before calibration. Calibration of the crop parameters was necessary to significantly improve the model's predictions. The parameter values of the reference and calibrated cultivars are summarized in Table 4.

The emergence date predicted with Pactol was 18 days too late in 1998, 13 days too late in 2001, and 11 days too late in 2002. The predicted date was also a few days later than the observed date in 1994, 1996, and 2008. In STICS, calculation of the emergence date is a function of soil temperature, soil moisture, and the sum of degree days between seeding and germination. Additionally, three parameters determine shoot elongation after germination. The sensitivity of emergence to soil moisture is controlled by the sensrsec parameter, which is a crop parameter that can be given a value between 0 and 1 . If sensrsec $=1$, the effect of soil dryness on root growth is only seen when water content is below the wilting point. As the value gets closer to 0 , the effect of soil moisture on emergence becomes more important (low soil moisture will lead to later emergence).

Before any calibration was performed, the predictions for soil moisture and soil temperature after seeding were examined. Figures 2a,b represent the temporal changes in soil moisture and temperature during the 1998 maize crop at the

a

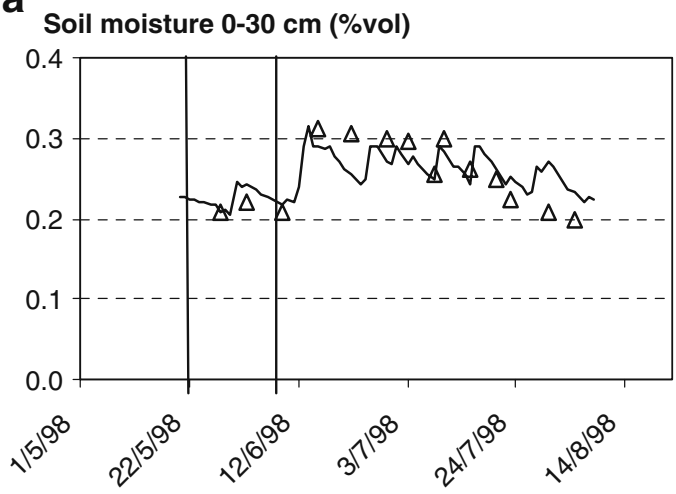

$\Delta$ Measured soil moisture
Ottawa CFIA site. For both variables, the predictions were close to the measurements and did not explain the delay in emergence. The sensrsec parameter was raised from 0.0 to 0.5 (emergence less sensitive to low soil moisture; same value as for wheat or soybean) and, with no change to the sum of degree days between seeding and germination, the calculated emergence date was 24 May, only 4 days after the observed date. After this adjustment, the calculated emergence dates were significantly closer to the observed dates for all years. The time between seeding and emergence ranged from 7 to 12 days. These values were within the range of variation reported by Liu et al. (2004) for maize in southern Ontario.

This calibration also improved the LAI and biomass predictions. The RMSE values were 0.25 (12.2\%) for LAI and 0.7 tha $^{-1}(9 \%)$ for biomass. Biomass was still slightly underestimated, by $0.3 \mathrm{tha}^{-1}(4 \%)$, whereas the bias was less than $0.05(<2 \%)$ for LAI. The calibration of RUE could reduce this small bias. In STICS, three parameters describe RUE: efcroijuv, efcroiveg, and efcroirepro, during the juvenile, vegetative, and grain-filling phases, respectively. In STICS, RUE parameters are used for shoot biomass calculation only. Biomass underestimation started in July (the middle of the vegetative phase), so only the efcroiveg and efcroirepro parameters were calibrated. These two parameters were initially set at $3.8 \mathrm{~g}$ dry matter (DM) per megajoule intercepted. Tollenaar and Aguilera (1992) showed that the difference in crop growth rate between an old cultivar (Pride 5, released in 1959) and a new one (Pioneer 3902, released in 1988) was 33\% and approximately $80 \%$ of that difference could be attributed to the higher RUE of the new cultivar. In their study, those researchers calculated a 15-day average RUE of $3.78 \mathrm{gDM} \mathrm{MJ}^{-1}$ from 4 to 6 weeks post-silking. Therefore, maximum RUE can be expected to be slightly higher than $3.8 \mathrm{gDM} \mathrm{MJ}^{-1}$. Loomis and Amthor (1999) predicted a potential maximum RUE of

b

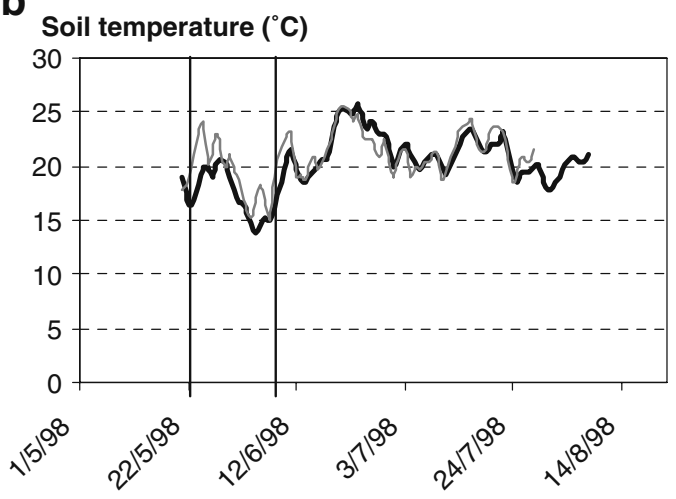

Fig. 2 Measured and predicted soil moisture (a) and temperature (b) in 1998 at the Ottawa CFIA site. The potential emergence date is delimited by the two vertical lines 
about $4.6 \mathrm{gDM} \mathrm{MJ}^{-1}$. In 1998, measured average RUE during July and August was $3.1 \mathrm{gDM} \mathrm{MJ}^{-1}$. The original calibration of potential RUE (efcroiveg and efcroirepro $=$ $3.8 \mathrm{gDM} \mathrm{MJ}^{-1}$ ) gave an average RUE of $2.9 \mathrm{gDM} \mathrm{MJ}^{-1}$ during the same period. Based on the year 1998, and in order to minimize RUE underestimation, maximum RUE was adjusted to $4.0 \mathrm{gDM} \mathrm{MJ}^{-1}$. This value is similar to the one used in the CropSyst model for maize grown in the US.

Figures $3 \mathrm{a}-\mathrm{d}$ present the LAI and biomass predictions compared to the measurements before (Pactol) and after (CanMaiisNE) the calibration of the phenological parameters and the calculation of the emergence date and RUE. The calibration resulted in a great improvement in predicted LAI and biomass. After the calibration, there was almost no bias, and the RMSE was classified as good for LAI (12.2\%) and excellent for biomass (5.4\%).

According to the study by Dwyer et al. (1999), the estimated duration of the growing season was about 5-8 days longer in Woodstock (southern Ontario, $150 \mathrm{~km}$ northeast of Woodslee) than in Ottawa. Most of this increase was due to a longer duration of grain filling. Because of the longer growing season, two parameters for CanMaiisSE were calibrated. The duration of grain filling (stdrpmat) was increased by 55 degree days, which corresponds to an increase of about 6-7 days with degree days of $9^{\circ} \mathrm{C}$ (average degree days during the growing

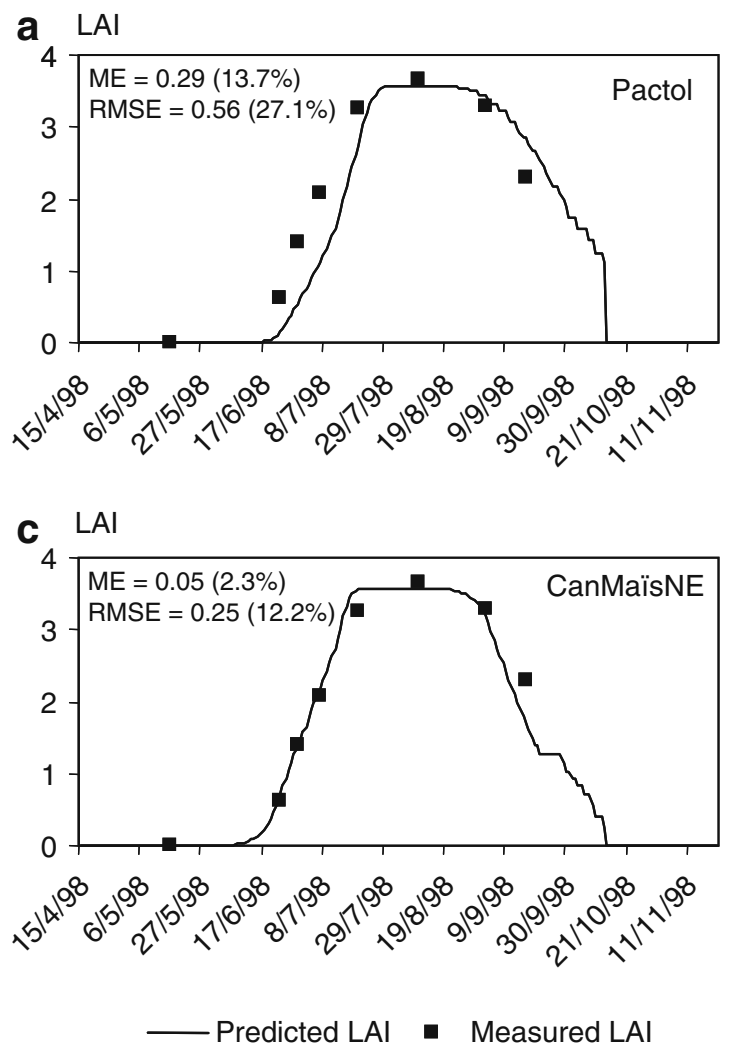

Fig. 3 Model performance using the original cultivar Pactol (a, b) and the newly calibrated cultivar CanMaïsNE $(\mathbf{c}, \mathbf{d})$ for predicting leaf area index (LAI) and shoot dry biomass at the Ottawa CFIA site in 1998. season with $\left.\mathrm{Tb}=8^{\circ} \mathrm{C}\right)$. The maximal lifespan of an adult leaf (durvieF) was also increased from 210 to 220 to take into account the longer period of green LAI.

\subsection{Cultivar performance evaluation in the Mixedwood Plains ecozone}

First, the performance of the calibrated model with respect to the two new cultivars was evaluated at the St-Jean site in order to determine which cultivar performed better. The LAI and biomass predictions were similar, but the yield predictions were significantly greater with CanMaïsSE than with CanMaïsNE. With CanMaïsNE, the yields were underestimated (19.8\%) and the RMSE was close to $20 \%$, whereas the model underestimated grain yield by $7 \%$ for CanMaïsSE (and the RMSE was $8.2 \%$ ). Although available CHU and cumulative GDD were almost similar between Ottawa and St-Jean, the average seeding date was almost 10 days later at the Ottawa site than at St-Jean. Considering that the harvest dates were close at the two sites, the growing season (from seeding to harvest) was about 10 days longer at St-Jean than at Ottawa. The earlier seeding date and longer growing season at St-Jean explain why CanMaïsSE performed better than CanMaïsNE at that site. This result suggests that seeding date is a critical variable
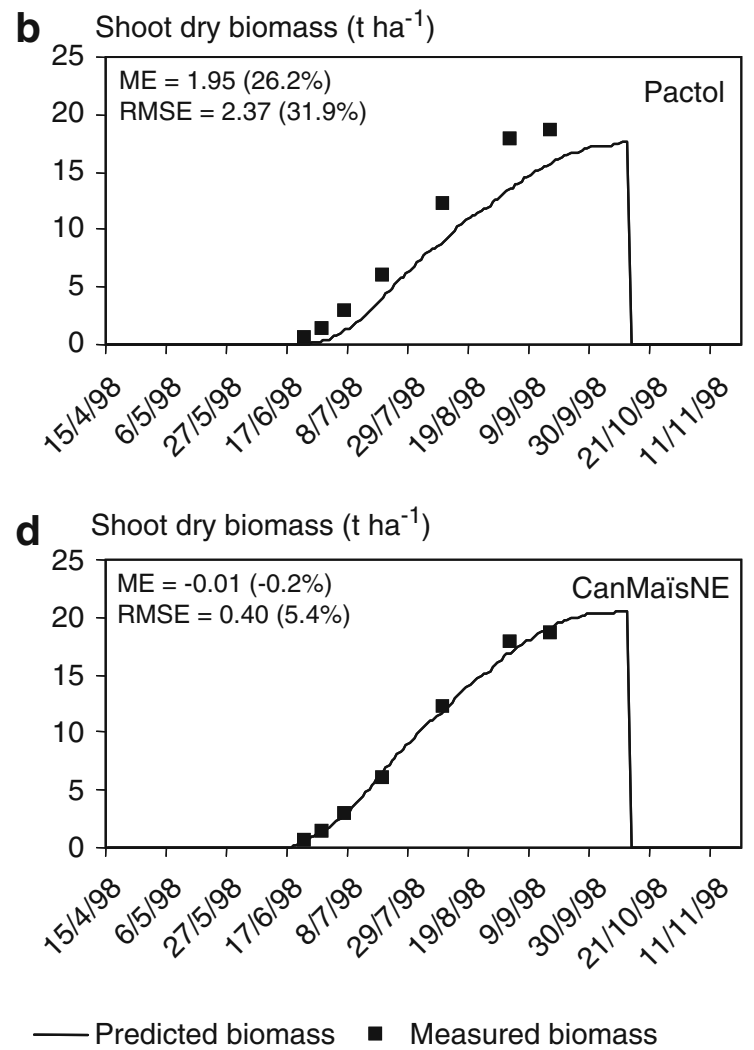

Statistical criteria (mean error [ME] and root mean square error [RMSE]) for each simulation are indicated in the graph 
for maize modeling in Eastern Canada, not only because it affects biomass and yield accumulation but also because a large delay in seeding date can influence the choice of cultivar.

Phenological stages were predicted very well by both cultivars. The predicted emergence dates were similar to the actual emergence date at Ottawa CFIA. Emergence dates were not recorded at the other two sites. The predicted beginning of grain filling was between 14 and 24 August at St-Jean, between 10 and 27 August at Ottawa CFIA, and between 5 August and 2 September at Woodslee. The beginning of grain filling was not observed at St-Jean and Woodslee, but the observed dates at Ottawa CFIA (from 8 to 26 August) were close to the predicted dates. The duration of grain filling was comparable at St-Jean and Ottawa CFIA (about $48 \pm 5$ days). Although CanMaïsSE, which was used mainly at Woodslee, presented a longer duration of grain filling (in degree days), the predicted duration time in days was shorter (about $35 \pm$ 5 days) at Woodslee because of higher temperatures in this southern location.

Figure 4 shows the measured and predicted yields at the three study sites. On average, the yield predictions were very good, with a bias close to 0 , and the RMSE was about $1.1 \mathrm{tha}^{-1}(14.4 \%)$. The poorest prediction occurred in field 42 at the Woodslee site in 2005. The predicted yield was greatly underestimated (by 4.1 tha $^{-1}$ ) because of severe water stress from May to mid-July (45.2 $\mathrm{mm}$ precipitations), which affected crop growth for the rest of the season. The low precipitations may have been compensated for by the capillary rise of groundwater, which can be close to the soil surface during the beginning of the growing season (Yang et al. 2007). However, this impact was not simulated in the model.

Figure 5 shows the comparison between the predicted and measured LAI and shoot dry biomass values with CanMaïsNE and CanMaïsSE at the St-Jean, Ottawa CFIA, and Woodslee sites. The statistical criteria (ME and RMSE) are summarized in Table 5.
The predicted LAI was acceptable at both sites, with the RMSE falling between 0.5 and 0.6 (about 30\%). The LAI was slightly overestimated at the Ottawa CFIA site (7.4\%) and was overestimated by $16.1 \%$ at the St-Jean site. At the Ottawa CFIA site, however, four of the 68 values were greatly overestimated, specifically the last two LAI measurements in 1994 and 1996 (around mid-September and mid-October in both cases). For these 2 years, the overestimation may have resulted from the use of old cultivars that did not present the stay-green capacity of newer cultivars. Indeed, several studies show that recent cultivars tend to keep their green leaves longer in the seedfilling period (Tollenaar and Aguilera 1992; Rajcan and Tollenaar 1999). At the St-Jean site, the LAI was predicted very well for 2004 and 2005, with no bias and an RMSE value of $15.9 \%$. Most of the scattering was due to the years 2006 and 2007. In 2006, the maximum LAI was predicted very well, but the difference between the predicted and measured values was due to a small time lag (the predicted LAI was about 10 days ahead of the measured LAI values). In 2007, there was no time lag, but the maximum LAI was overestimated by about 0.8 .

There was good agreement between the predicted and measured biomass at the St-Jean and Ottawa CFIA sites. The bias was small $\left(<0.5\right.$ tha $\left.^{-1}\right)$, and the RMSE was less than 1 tha $^{-1}(21.8 \%$ of the average biomass at St-Jean and $13.1 \%$ of average biomass at Ottawa CFIA). At Woodslee, the predictions were less accurate. On average, the biomass was underestimated by 3.1 tha $^{-1}(23.5 \%)$, and the RMSE was $2.6(19.9 \%)$. Most of this underestimation was due to lower biomass predictions during the growing season, and the final biomass was slightly better predicted (underestimation of $12 \%$ in $1997,18 \%$ in 1998 , and $15 \%$ in 1999). The weather conditions in field 42 at the Woodslee site (in 1997, 1998, and 1999) were drier than the climate average. The precipitation deficit was $108 \mathrm{~mm}$ in 1997, $159 \mathrm{~mm}$ in 1998, and $180 \mathrm{~mm}$ in 1999. In the field, this deficit could
Fig. 4 Evaluation of the maize yield predictions using the cultivars CanMaïsSE and CanMaïsNE at the St-Jean, Ottawa CFIA, and Woodslee sites

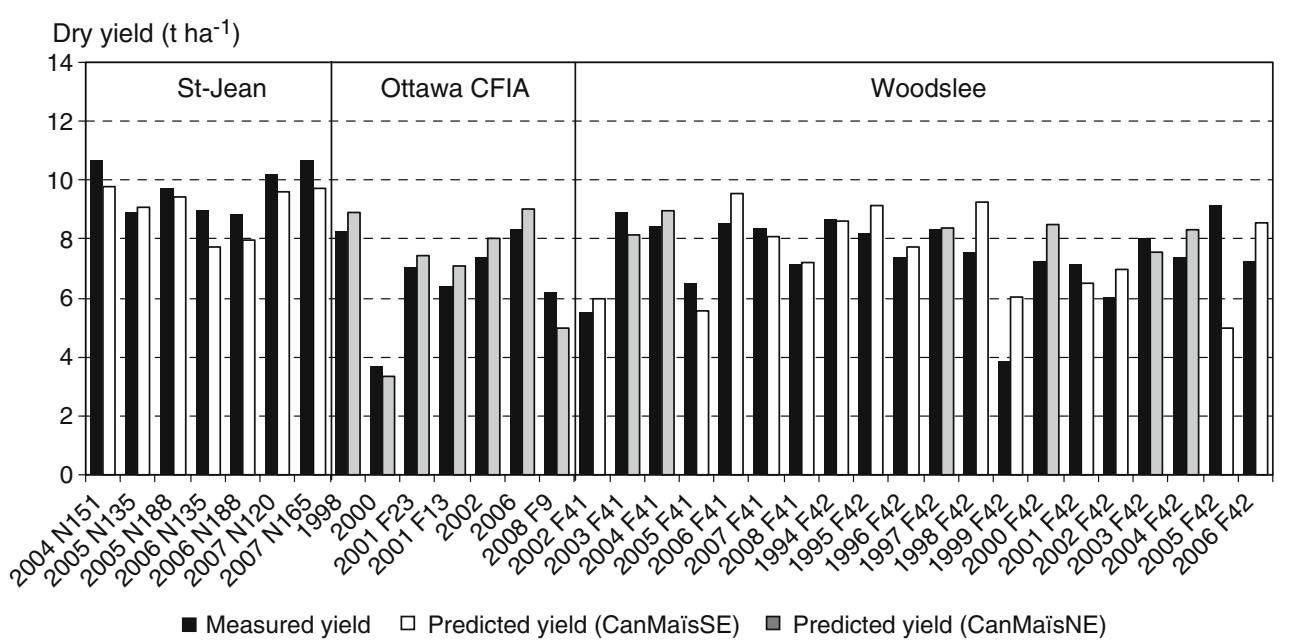




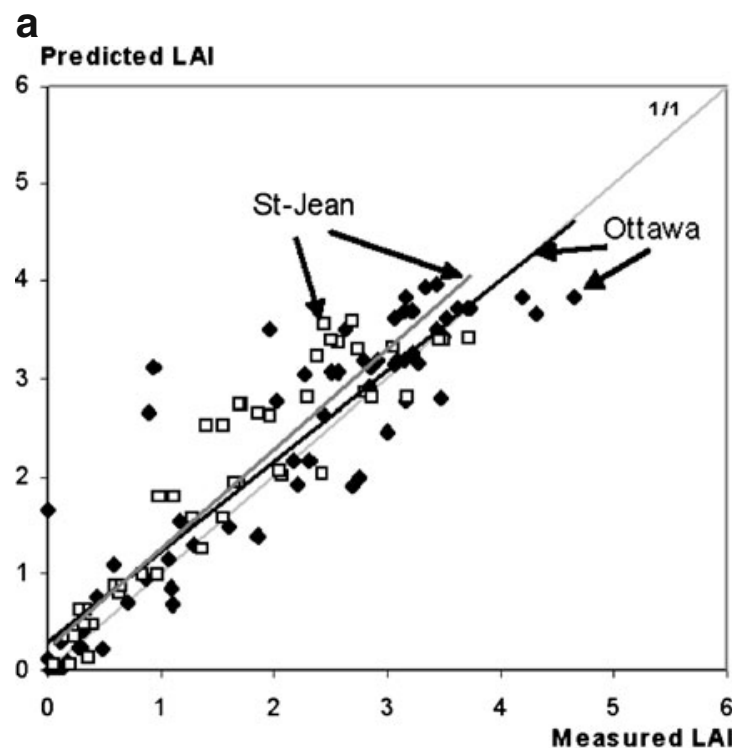

Fig. 5 a Evaluation of the leaf area index (LAI) predictions of the cultivars CanMaïsNE and CanMaïsSE at the St-Jean $(y=1.03 x+0.22$; $\left.R^{2}=0.87\right)$ and Ottawa CFIA $\left(y=0.93 x+0.30 ; R^{2}=0.84\right)$ sites. b Evaluation of the shoot dry biomass predictions of the cultivars

have been partly compensated for by the capillary rise of groundwater, particularly in 1998, given that most of that year's water stress occurred in May and June, when the groundwater level was high (Yang et al. 2007).

Previous calibration and performance evaluation studies with either new crops or new cultivars in the STICS model provide guidance on what range of ME and RMSE values are acceptable. For the performance evaluation of a new crop (linseed), Flénet et al. (2004) predicted that, for biomass, an RMSE of about $20 \%$ and a small bias $(-2.4 \%)$ are acceptable, whereas for LAI, an RMSE of about $50 \%$ and a ME of about $18 \%$ mean that some improvements are required. Corre-Hellou et al. (2009) found that simulations of shoot dry biomass were satisfac-

Table 5 Mean error (ME) and root mean square error (RMSE) of the predicted leaf area index (LAI) and biomass for the three study sites (irrespective of cultivar) and the two new cultivars (irrespective of site)

\begin{tabular}{llllll}
\hline & & RMSE & RMSE \% & ME & ME \% \\
\hline \multirow{2}{*}{ St-Jean } & LAI & 0.5 & 30.6 & -0.3 & -16.1 \\
& Biomass & 0.9 & 21.8 & -0.3 & -8.1 \\
Ottawa CFIA & LAI & 0.6 & 28.1 & -0.2 & -7.4 \\
& Biomass & 0.9 & 13.1 & 0.2 & 2.8 \\
Woodslee & LAI & - & - & - & - \\
& Biomass & 3.1 & 23.5 & 2.6 & 19.9 \\
CanMaïsNE & LAI & 0.6 & 28.1 & -0.2 & -7.4 \\
& Biomass & 1.4 & 17.5 & 0.4 & 5.3 \\
CanMaïsSE & LAI & 0.5 & 30.6 & -0.3 & -16.1 \\
& Biomass & 1.4 & 25.2 & 0.1 & 2.4 \\
\hline
\end{tabular}

b

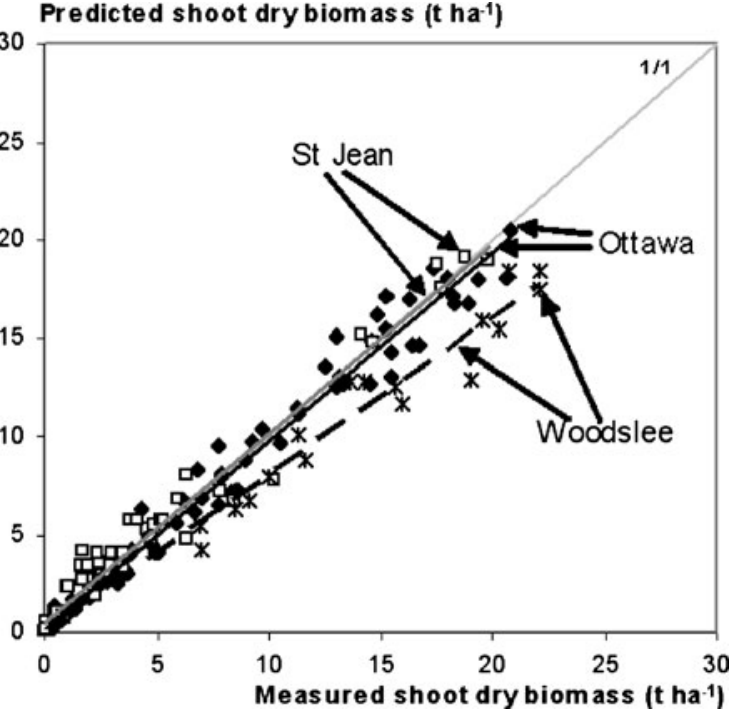

CanMaïsNE and CanMaïsSE at the St-Jean $\left(y=0.96 x+0.51 ; R^{2}=\right.$ 0.97), Ottawa CFIA $\left(y=0.96 x+0.10 ; R^{2}=0.98\right)$, and Woodslee $(y=$ $\left.0.80 x+0.03 ; R^{2}=0.96\right)$ sites

tory with an RMSE of $17-21 \%$ for pea and marginally satisfactory with an RMSE of 25-35\% for barley.

After model calibration, the RMSE was close to or below $30 \%$ for the LAI and biomass predictions and below $20 \%$ for the yield predictions. According to previous studies, these results confirm that the definition of two cultivars is sufficient to achieve good predictions of yield, LAI, and biomass over the entire studied geographical area. The model gave good predictions for the areas where CanMaïsNE was used (2,500 $2,900 \mathrm{CHU})$. It also gave acceptable yield predictions when it was used in cases of delayed seeding in high-CHU areas such as southern Ontario. The model also performed well for CanMaïsSE (area with 2,900-3,300 CHU). However, additional LAI and biomass measurements would be necessary to complete its evaluation for high-CHU areas $(3,200$ $3,300 \mathrm{CHU})$. Although yields were correctly predicted at Woodslee, biomass seemed to be slightly underestimated. The actual dataset does not make it possible to determine whether the underestimation is due to a poor simulation of water stress or to incorrect cultivar parameters (such as LAI dynamics). Southern Ontario could constitute the southern limit of the application of the set of parameters calibrated using the Ottawa dataset. However, a comparison of the average maximum LAI for CanMaïsSE (around 4.2) with the value for northern US cultivars in rainfed conditions reveals that the highest LAI values are comparable (Suyker et al. 2004; Williams et al. 2006).

These results also show that seeding date is a critical parameter, not only for predicting biomass and LAI dynamics but also for determining which kind of cultivar (in terms of $\mathrm{CHU}$ rating) should be used. In Eastern 
Canada, where cold and wet soils are coupled with a short growing season, the time of seeding has a major impact on crop growth and final yield, as is the case in the northern US maize belt. For crop modeling at a regional scale, this fact demonstrates the value of using remote sensing to reestimate management parameters such as seeding date.

It was decided to calibrate the plant parameters controlling emergence because a large difference between the measured and calculated emergence dates was observed, and to calibrate RUE because of the genetic improvement of the new cultivars (Tollenaar and Aguilera 1992). The value of $4 \mathrm{~g} \mathrm{MJ}^{-1}$ is used in other crop models, such as EPIC or CropSyst, adapted to northern US maize belt cultivars. The base temperature was not calibrated, because the one used in STICS $\left(8^{\circ} \mathrm{C}\right)$ seemed adequate and was comparable to the base temperature used in EPIC and CropSyst as well as the one reported by Lizaso et al. (2007).

\section{Conclusion}

The calibration of two maize cultivars representative of Eastern Canada required the adjustment of only a few parameters, confirming the adequate parameterization of the generic plant parameters of the STICS crop model. Evaluation of STICS showed that the cultivar CanMaïsNE provided good predictions of LAI, biomass, and yield in the area around Ottawa, with 2,500-2,900 CHU. The cultivar CanMaïsSE, calibrated for 2,900-3,300 CHU, performed well at the StJean site (near Montreal), where the seeding date was earlier than in the Ottawa region, allowing cropping of a higher-CHU cultivar. At Woodslee (southern Ontario), CanMaïsSE gave good predictions for most of the years because the available GDD and solar radiation were significantly higher there than at the two other sites. However, when seeding was delayed as a result of wet springs and the inability of agricultural machinery to access the fields, CanMaïsNE performed better. At the Woodslee site, the yield predictions were good, but biomass was underestimated. Additional LAI and biomass data would be necessary to confirm this trend. However, the two cultivars allowed the estimation of LAI, biomass, and yield over a large area that covers three degrees of latitude and $10^{\circ}$ of longitude and is characterized by an important temperature gradient. This result represents a great advance in terms of the future possibilities for crop modeling at the regional scale when coupled with soil databases, gridded weather data, and remote sensing data. Moreover, this work could be the basis for future studies performed to (1)more precisely assess the $N$ fertilization recommendation according to climatic variability in Eastern Canada, and (2)evaluate the suitability of maize cropping in northern areas of Eastern Canada, according to climatic trends.
Acknowledgments The authors would like to thank all the research technicians and professionals (CFIA: Dave Dow, Christophe Forget, Stuart Admiral, and Scott Patterson; Woodslee: Wayne Calder and Vic Bernyk; St-Jean: Edith Fallon) and all the students who participated in the field measurements and data handling at the various sites. This work was jointly funded by Agriculture and Agri-Food Canada and the Canadian Space Agency (Government Related Initiatives Program).

\section{References}

Agriculture and Agri-Food Canada (2010) Canada: grains and oilseeds outlook, Publ. 1496-967X, AAFC, Ottawa, ON

Arnold CY (1960) Maximum-minimum temperatures as a basis for computing heat units. Proc Am Soc Hortic Sci 76:682-692

Brisson N, Mary B, Ripoche D, Jeuffroy MH, Ruget F, Nicoullaud B, Gate P, Devienne-Barret F, Antonioletti R, Durr C, Richard G, Beaudoin N, Recous S, Tayot X, Plenet D, Cellier P, Machet JM, Meynard JM, Delécolle R (1998) STICS: a generic model for the simulation of crops and their water and nitrogen balances. I. Theory and parameterization applied to wheat and corn. Agronomie 18:311-346. doi:10.1051/agro:19980501

Brisson N, Ruget F, Gate P, Lorgeou J, Nicoullaud B, Tayot X, Plenet D, Jeuffroy MH, Bouthier A, Ripoche D, Mary B, Justes E (2002) STICS: a generic model for simulating crops and their water and nitrogen balances. II. Model validation for wheat and maize. Agronomie 22:69-92. doi:10.1051/agro:2001005

Brisson N, Gary C, Justes E, Roche R, Mary B, Ripoche D, Zimmer $\mathrm{D}$, Sierra J, Bertuzzi P, Burger $\mathrm{P}$, Bussière F, Cabidoche YM, Cellier P, Debaeke P, Gaudillère JP, Hénault C, Maraux F, Seguin B, Sinoquet H (2003) An overview of the crop model STICS. Eur J Agron 18:309-332. doi:10.1016/S1161-0301(02)00110-7

Brown D.M., Bootsma A. (1993) Crop heat units for corn and other warm season crops in Ontario, Publ. 111/31, Ontario Ministry of Agriculture, Food and Rural Affairs, Ottawa, ON

Centre de référence en agriculture et agroalimentaire du Québec (2003) Guide de référence en fertilisation, 1st edn. CRAAQ, Sainte-Foy, QC

Chen JM, Black TA (1992) Defining leaf area index for non-flat leaves. Plant Cell Environ 15:421-429. doi:10.1111/j.13653040.1992.tb00992.x

Chipanshi AC, Ripley EA, Lawford RG (1997) Early prediction of spring wheat yields in Saskatchewan from current and historical weather data using the CERES-wheat model. Agric For Meteorol 84:223-232. doi:10.1016/S0168-1923(96)02363-5

Chipanshi AC, Ripley EA, Lawford RG (1999) Large-scale simulation of wheat yields in a semi-arid environment using a crop-growth model. Agric Syst 59:57-66. doi:10.1016/S0308-521X(98)00082-1

Corre-Hellou G, Faure M, Launay M, Brisson N, Crozat Y (2009) Adaptation of the STICS intercrop model to simulate crop growth and $\mathrm{N}$ accumulation in pea-barley intercrops. Field Crops Res 113:72-81. doi:10.1016/j.fcr.2009.04.007

Dwyer LM, Ma BL, Evenson L, Hamilton RI (1994) Maize physiological traits related to grain yield and harvest moisture in mid- to short-season environments. Crop Sci 34:985-992. doi:10.2135/cropsci1994.0011183X003400040029x

Dwyer LM, Stewart DW, Carrigan L, Ma BL, Neave P, Balchin D (1999) A general thermal index for maize. Agron J 91:940-946. doi:10.2134/agronj1999.916940x

Flénet F, Villon P, Ruget F (2004) Methodology of adaptation of the STICS model to a new crop: spring linseed (Linum usitatissimum, L.). Agronomie 24:367-381. doi:10.1051/agro:2004032

Gonzalez-Dugo V, Durand JL, Gastal F (2010) Water deficit and nitrogen nutrition of crops. A review. Agron Sustain Dev 30:529-544 
Jamieson PD, Porter JR, Wilson DR (1991) A test of the computer simulation model ARCWHEAT1 on wheat crops grown in New Zealand. Field Crops Res 27:337-350. doi:10.1016/0378-4290 (91)90040-3

Jégo G, Pattey E, Bourgeois G, Morrison MJ, Drury CF, Tremblay N, Tremblay G (2010) Calibration and performance evaluation of soybean and spring wheat cultivars using the STICS crop model in Eastern Canada. Field Crops Res 117:183-196. doi:10.1016/j. fcr.2010.03.008

Jones JW, Hoogenboom G, Porter CH, Boote KJ, Batchelor WD, Hunt LA, Wilkens PW, Singh U, Gijsman AJ, Ritchie JT (2003) The DSSAT cropping system model. Eur J Agron 18:235-265. doi:10.1016/S1161-0301(02)00107-7

Liu W, Tollenaar M, Stewart G, Deen W (2004) Response of corn grain yield to spatial and temporal variability in emergence. Crop Sci 44:847-854. doi:10.2135/cropsci2004.0847

Lizaso JI, Boote KJ, Cherr CM, Scholberg JMS, Casanova JJ, Judge J, Jones JW, Hoogenboom G (2007) Developing a sweet corn simulation model to predict fresh market yield and quality of ears. J Am Soc Hortic Sci 132:415-422

Loomis RS, Amthor JS (1999) Yield potential plant assimilatory capacity, and metabolic efficiencies. Crop Sci 39:1584-1596. doi:10.2135/cropsci1999.3961584x

Ma BL, Dwyer LM (1998) Nitrogen uptake and use of two contrasting maize hybrids differing in leaf senescence. Plant Soil 199:283291. doi:10.1023/A:1004397219723

Monteith JL (1965) Evaporation and environment. Symp Soc Exp Biol 19:205-234

Moulin AP, Beckie HJ (1993) Evaluation of the CERES and EPIC models for predicting spring wheat grain yield over time. Can J Plant Sci 73:713-719. doi:10.4141/cjps93-093

Ontario Ministry of Agriculture, Food and Rural Affairs (2002) Agronomy guide for field crops, Publ. 811, OMAFRA, Ottawa, ON

Pokorný R, Marek MV (2000) Test of accuracy of LAI estimation by LAI-2000 under artificially changed leaf to wood area proportions. Biol Plant 43:537-544. doi:10.1023/A:1002862611176

Porter JR, Semenov MA (2005) Crop responses to climatic variation. Phil Trans R Soc B 360:2021-2038. doi:10.1098/rstb.2005.1752

Prévot L, Chauki H, Troufleau D, Weiss M, Baret F, Brisson N (2003) Assimilating optical and radar data into the STICS crop model for wheat. Agronomie 23:297-303. doi:10.1051/ agro:2003003

Rajcan I, Tollenaar M (1999) Source: sink ratio and leaf senescence in maize. I. Dry matter accumulation and partitioning during grain filling. Field Crops Res 60:245-253. doi:10.1016/S0378-4290 (98)00142-7

Ritchie JT, Otter S (1984) Description and performance of CERESwheat: a user-oriented wheat yield model. USDA-ARS-SR
Grassland Soil and Water Research Laboratory, Temple, TX, pp $159-175$

Roloff G, de Jong R, Nolin MC (1998) Crop yield, soil temperature and sensitivity of EPIC under central-eastern Canadian conditions. Can J Soil Sci 78:431-439. doi:10.4141/S97-087

Saxton KE, Rawls WJ (2006) Soil water characteristic estimates by texture and organic matter for hydrologic solutions. Soil Sci Soc Am J 70:1569-1578. doi:10.2136/sssaj2005.0117

Singh AK, Tripathy RT, Chopra UK (2008) Evaluation of CERESwheat and CropSyst models for water-nitrogen interactions in wheat crop. Agric Water Manage 95:776-786. doi:10.1016/j. agwat.2008.02.006

Spiertz JHJ (2010) Nitrogen, sustainable agriculture and food security. A review. Agron Sustain Dev 30:43-55

Stockle CO, Martin SA, Campbell GS (1994) CropSyst, a cropping systems simulation model: water/nitrogen budgets and crop yield. Agric Syst 46:335-359. doi:10.1016/0308-521X(94)90006-2

Suyker AE, Verma SB, Burba GG, Arkebauer TJ, Walters DT, Hubbard KG (2004) Growing season carbon dioxide exchange in irrigated and rainfed maize. Agric For Meteorol 124:1-13. doi:10.1016/j.agrformet.2004.01.011

Thomas H, Smart CM (1993) Crops that stay green. Ann Appl Biol 123:193-219. doi:10.1111/j.1744-7348.1993.tb04086.x

Tollenaar M (1991) Physiological basis of genetic improvement of maize hybrids in Ontario from 1959 to 1988. Crop Sci 31:119 124. doi:10.2135/cropsci1991.0011183X003100010029x

Tollenaar M, Aguilera A (1992) Radiation use efficiency of an old and a new maize hybrid. Agron J 84:536-541. doi:10.2134/ agronj1992.00021962008400030033x

Tollenaar M, Wu J (1999) Yield improvement in temperate maize is attributable to greater stress tolerance. Crop Sci 39:1597-1604. doi: $10.2135 /$ cropsci1999.3961597x

Touré A, Major DJ, Lindwall CW (1995) Comparison of five wheat simulation models in southern Alberta. Can J Plant Sci 75:61-68. doi: $10.4141 /$ cjps $95-010$

Walker GK (1989) Model for operational forecasting of Western Canada wheat yield. Agric For Meteorol 44:339-351. doi:10.1016/0168-1923(89)90027-0

Williams JR, Jones CA, Dyke PT (1984) A modeling approach to determining the relationship between erosion and soil productivity. Trans ASAE 27:129-144

Williams MM II, Boydston RA, Davis AS (2006) Canopy variation among three sweet corn hybrids and implications for light competition. Hort Science 41:1449-1454

Yang CC, Prasher SO, Wang S, Kim SH, Tan CS, Drury C, Patel RM (2007) Simulation of nitrate-N movement in southern Ontario, Canada with DRAINMOD-N. Agric Water Manage 87:299-306. doi:10.1016/j.agwat.2006.07.009 